\title{
Two new species of European Stevenia Robineau-Desvoidy (Diptera: Rhinophoridae) and a key to the Palaearctic species
}

\author{
PIERFILIPPO CERRETTI ${ }^{1} \&$ THOMAS PAPE ${ }^{2}$ \\ ${ }^{1}$ Centro Nazionale Biodiversità Forestale - Corpo Forestale dello Stato, via Carlo Ederle 16/a, I-37100 Verona, Italy. \\ E-mail:pierfilippocerretti@yahoo.it; pierfilippo.cerretti@entecra.it \\ ${ }^{2}$ Zoological Museum, Entomology Department, Universitetsparken 15, DK-2100 Copenhagen, Denmark. E-mail: tpape@snm.ku.dk
}

\begin{abstract}
Two new species of Stevenia are described from Europe: Stevenia etrusca sp. nov. (Italian mainland: Toscana) and $S$. palermitana sp. nov. (Italy: Sicily, Palermo prov.). A key to all known Palaearctic species of the genus is provided.
\end{abstract}

Key words: Rhinophoridae, Stevenia, Europe, Italy, new species, key to species

\section{Introduction}

The family Rhinophoridae contains some 150 named species worldwide (Pape 1998; Pape \& Arnaud 2001; Thompson 2006). Europe, and particularly the Mediterranean biome, is remarkably rich in species, which can only partly be ascribed to its longer and more thorough taxonomic exploration. Following Herting's (1961) monograph on the Palaearctic Rhinophoridae, all new species of this family have been described from outside Europe (Peris 1963; Herting 1966; Crosskey 1977; Kugler 1978; Báez 1979a,b, 1988; Colless 1994; Pape \& Kurahashi 1994; Pape 1985, 1987a,b, 1997; Pape \& Arnaud 2001).

The genus Stevenia Robineau-Desvoidy was previously known from twenty-one species: nineteen from the W-Palaearctic subregion (Canary Islands [1 endemic], central and southern Europe, North Africa and Middle East) (Crosskey 1977; Herting 1961, 1993); one Afrotropical from Socotra (Crosskey 1977); and one Oriental from Sri Lanka.

Very little is known on the biology of Stevenia spp., but they are expected to be parasites of woodlice (Crustacea: Isopoda) like other Rhinophoridae. Breeding records exist for S. atramentaria (Meigen), which is reported as parasitizing Porcellio scaber Latreille (Porcellionidae), Philoscia affinis Verhoeff (Philosciidae) and Tracheoniscus arcuatus Budde-Lund (Trachelipodidae), possibly even Oniscus asellus Linnaeus (Herting 1961, Crosskey 1977); and S. signata Mik, which has been bred from Armadillidium vulgare (Latreille) and A. frontirostre Budde-Lund (Bürgis 1991, 1992).

We are here describing two new species of Stevenia, from mainland Italy and from the Italian island of Sicily, respectively. A key to separate the new species from their congeners in the Palaearctic Region is provided.

\section{Material and methods}

The dissection of male terminalia was carried out following the method described in detail by O'Hara (2002). The terminalia of each dissected male are preserved in glycerine in a small plastic vial, which is pinned 
together with the source specimen. Digital images were taken using a Nikon DS-L1 camera mounted on a Leica MZ 12.5 stereoscopic microscope and processed by AutoMontage Pro, version 5.03.0096. Terminology of the external morphology follows Merz and Haenni (2000), except for the antenna (Stuckenberg 1999). Measurements and ratios of the head follow Tschorsnig and Richter (1998).

Abbreviations (and Diptera curators) for depositories cited in this work:

CNBF Insect Collection, Centro Nazionale Biodiversità Forestale, Verona, Italy (F. Mason).

MZUR Museum of Zoology, Università degli Studi di Roma "La Sapienza", Rome, Italy (A. Vigna Taglianti).

CPC Private collection of P. Cerretti.

ZMUC Zoological Museum, University of Copenhagen, Denmark (T. Pape).

\section{Taxonomy}

\section{Stevenia Robineau-Desvoidy, 1830}

Stevenia Robineau-Desvoidy, 1830: 220 [original description]. Type species: Stevenia tomentosa Robineau-Desvoidy, 1830: 220 [= Tachina atramentaria Meigen, 1824: 291], by designation of Desmarest in d'Orbigny (1848: 32) [see Evenhuis \& Thompson 1990].

References. Belanovsky (1951) [Ukrainian species]; Herting (1961) [Palaearctic revision]; Crosskey (1977) [redescription, biogeography, bionomics, taxonomy]; Kugler (1978) [Israelian species]; Báez (1979a) [Canary Islands species]; Tschorsnig (1985) [male terminalia, taxonomic notes]; Pape (1986) [phylogenetic position]; Pape (1989) [revision of Rondani types]; Herting (1993) [Palaearctic catalogue]; Pape (1998) [key to Palaearctic genera]; Verves (2005) [Ukrainian species].

\section{Stevenia palermitana sp. nov.}

Type material. Holotype ${ }^{x}$ : ITALY - Sicily (Palermo prov.) / Bosco della Ficuzza 600-1000 m / Torretta Torre / hand net on low vegetation / 18.V.2004 / P. Cerretti, D. Birtele, G. Nardi, D. Whitmore leg. [MZUR]. Paratypes: ITALY - Sicily (Palermo prov.): $20^{x} 0^{x} 1 \stackrel{9}{ }$, same data as holotype [ZMUC]; $10^{x} 19$, Bosco della Ficuzza 600-1000 m / Torretta Torre / hand net on low vegetation / 18.V.2004 / P. Cerretti, D. Birtele, G. Nardi, D. Whitmore leg. [CPC, ZMUC]; 2 o $^{x} o^{x}$ Bosco della Ficuzza 600-1000 m / Torretta Torre / hand net on low vegetation / 05.V.2004, [same collectors] [CPC]; 1 o 2 우오, Bosco della Ficuzza 600-1000 m / (on Ferula communis) [Apiaceae] / 14.V.2004, [same collectors] [CPC, ZMUC]; 1 우, Bosco della Ficuzza 600-1000 m / (on Elaeoselinum asclepium) [Apiaceae] / 29.VII.2003 (hand net) / P. Cerretti, M. Tisato leg. [CPC]; 1 우, Bosco della Ficuzza 600-1000 m / Laghetti Coda di Riccio / N37.52329 E13.24032 / 19.V.2004 (hand net), [same collectors] [CPC]; 5 o o $^{x} 7$ 우우, Bosco della Ficuzza 885 m / Pulpito del Re / N37.53174 E13.23768 / (on Ferula communis) / 15.V.2004, [same collectors] [CNBF, CPC]; 1 우, Madonie - Piano Zucchi 1238 m, 21.V.2004, [same collectors] [ZMUC].

Etymology. The name refers to the province of the type locality (Palermo) and should be treated as a Latin adjective.

Diagnosis. Male with narrow frons and without proclinate orbital setae. Body entirely black except for the reddish or orangish posterior 1/2-1/4 of abdominal tergite 5; all abdominal tergites with dense microtrichosity.

Description. Male (measurements in square brackets refer to the holotype):

Length: $6.3-7.7 \mathrm{~mm}$. 
Colour. Head black with grey microtrichosity; area between gena and parafacial reddish; scape and pedicel black or dark brown, postpedicel black; palpus brown to dark-brown, sometimes yellowish apically. Thorax and legs black; presutural area with three broad longitudinal dark vittae. Upper and lower calypters whitish. Wing hyaline or slightly infuscate; tegula black, basicosta yellow, veins black or dark brown. Abdomen (Fig. 3) mainly black except for posterior $1 / 2-1 / 4$ of tergite 5 , which is red; tergites $2-4$ each with a transverse band of white microtrichosity on anterior $1 / 2-3 / 4$, interrupted medio-dorsally by a broad, longitudinal black stripe; tergite 5 with a non-interrupted band of microtrichosity on anterior 1/3-1/2. Epandrium black. Sternite 5 mainly yellow.

Head (Figs. 1, 2). Eye bare. Arista, thickened on about basal 1/5, covered with hairs at most as long as its basal diameter. First and second aristomere not longer than wide. Postpedicel about 0.9-[1.2] times as long as pedicel. Frons at its narrowest point 0.56-[0.69] times as wide as an eye in dorsal view. Ocellar setae well developed (usually shorter than the posterior frontal setae), proclinate. Medial (= inner) vertical setae strong, reclinate, sub-parallel to each other. Lateral (= outer) vertical setae not differentiated from the postocular setae. One or 2 reclinate upper orbital setae; no proclinate orbital setae. Eight to 9 frontal setae descending to the level of the middle of pedicel or slightly lower. Fronto-orbital plate with scattered, short, proclinate setulae. Parafacial with a row of 5-7 long and stout medioclinate setae on lower 3/4-4/5, and several short proclinate setulae (Figs 1, 2). Parafacial at its narrowest point 1.15-[1.38] times as wide as the postpedicel. Face and lower facial margin not visible in lateral view. Vibrissa usually well developed (sometimes not differentiated from sub-vibrissal setae), arising at level of lower facial margin. Facial ridge concave with robust setulae on lower 1/6-1/5. Genal dilation well developed. Gena in profile about 0.28-[0.40] times the vertical height of eye (height measured in the same vertical plane as height of head). Postocular setae relatively short, slightly bent forwards. Occiput convex, only with black setulae behind the postocular row. Prementum about 2.0-2.5 times as long as wide. Palpus sub-cylindrical with some setulae ventrally, dorsally and apically.

Thorax. Prosternum and proepisternum bare. Postpronotum with 4 (rarely 5) setae; the three strongest form a triangle. Scutum with 1-2 + 1-2 acrostichal, $2-3+3$ dorsocentral, $0-1+2-3$ intraalar, 2 posthumeral, 1 strong presutural, 2 notopleural, and 3 supraalar setae (first postsutural supraalar seta (= prealar) shorter than notopleural setae), postalar callus with 2 setae. Anatergite with a patch of setulae just below the base of lower calypter. Three katepisternal setae. One anepimeral seta well differentiated from adjacent setulae. Katepimeron bare. Scutellum with 3 pairs (basal, lateral and apical) of marginal setae; basal setae short, about 2/3-3/4 as long as laterals; lateral setae slightly longer than the crossed apicals. A pair of discal scutellar setae. Postmetacoxal area membranous.

Legs. Fore leg: Coxa with bare medial surface; tibia with 3-4 anterodorsal setae, without posterodorsal setae, preapical anterodorsal setae shorter than preapical dorsal one (preapical posterodorsal seta not differentiated); claws longer than tarsomere 5. - Mid leg: tibia with 3-4 anterodorsal setae, 3-6 posterodorsal setae, usually 1 posterior seta; ventral seta on mid tibia present or absent. - Hind leg: Posterior coxal margin bare; tibia with several anterodorsal and posterodorsal setae of irregular length and thickness, with 3 dorsal preapical setae.

Wing (Fig. 4). Costal spine very long, about 1.5-2.0 times as long as crossvein r-m. Second costal portion $\left(\mathrm{CS}_{2}\right)$ with short setulae ventrally. Base of $\mathrm{R}_{4+5}$ with 1-4 setulae. Section of $\mathrm{M}$ between crossveins $\mathrm{r}-\mathrm{m}$ and dm$\mathrm{cu}$ longer than the section between $\mathrm{dm}-\mathrm{cu}$ and bend of $\mathrm{M}$. Wing cell $\mathrm{r}_{4+5}$ distinctly petiolate, petiole $0.81-1.12$ times as long as post-angular portion of $\mathrm{M}$.

Abdomen. Middorsal depression on abdominal syntergite $1+2$ confined to anterior $1 / 3$ of that segment. Syntergite 1+2 with 1 pair of median marginal setae and one or more lateral marginals. Tergite 3 with a pair of median marginal and usually 1 pair of median discal setae (rarely absent). Tergite 4 with a row of marginal setae, 1-5 medio-discal setae. Tergite 5 with rows of marginal and discal setae. 


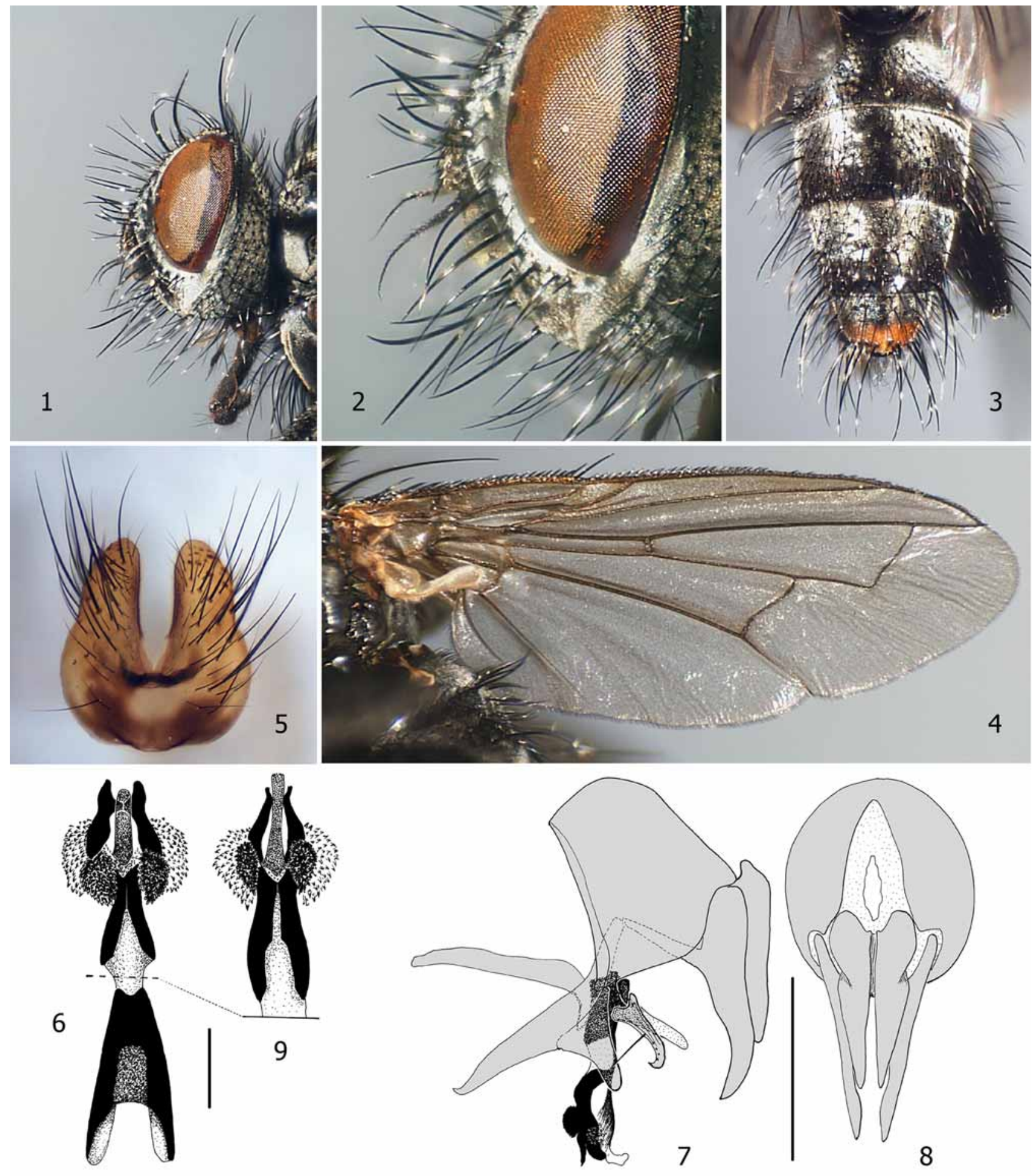

FIGURES 1-9. Stevenia spp. 1-8. S. palermitana sp. nov. (holotype). 1. Head in lateral view. 2. Detail of head, showing parafacial setae. 3. Abdomen in dorsal view. 4. Left wing in ventral view. 5. Sternite 5 in ventral view. 6. Aedeagus in ventral view, scale bar $0.1 \mathrm{~mm}$. 7. Male genitalia in left lateral view. 8. Epandrial complex in posterior view, scale bar 0.5 mm. 9. S. deceptoria (Italy: Sicily), distiphallus in ventral view, scale bar $0.1 \mathrm{~mm}$.

Terminalia (Figs. 5-8). Hind margin of sternite 5 with a deep cleft; lateral lobe large; medio-apical margin of lateral lobe with dense microtrichia (Fig. 5). Tergite 6 weakly sclerotized, divided into two hemitergites, joining segment $7+8$ by a membrane. Sternite 6 asymmetrical, articulated to segment $7+8$ on its left side and attached to it by a large membrane on its right side. Epandrium short and convex. Cerci (Figs. 7, 8) shorter 
than surstylus, with a dorso-medial suture, apically separated from each other. Surstylus (Figs 7, 8) pointed, long and curved forward in profile. Ejaculatory sclerite large and fan-shaped. Medial plate of hypandrium sub-rectangular in dorsal view; hypandrial arms long and sub-parallel (not encircling the base of the phallus). Bacilliform sclerites long. Pregonite sub-triangular. Postgonite long, narrow and hook-like with one long setula at mid-length. Epiphallus (Fig. 7) straight, well developed and weakly sclerotized. Distiphallus joining basiphallus by a dorsal sclerite and by a ventro-lateral membrane; lateroventral surface of distiphallus strongly sclerotized and covered with scale-like spinules (Fig. 6).

Female, differs from male as follows:

Length: $5.5-6.7 \mathrm{~mm}$.

Colour. Abdomen darker with basal band of microtrichosity much weaker and sometimes indistinct.

Head. Frons slightly wider, at its narrowest point $0.79-0.95$ times as wide as an eye in dorsal view. Fronto-orbital plate with 1-2 proclinate orbital setae. Parafacial (in lateral view) at its narrowest point 0.9-1.3 times as wide as the postpedicel. Gena in profile 0.3-0.4 times the vertical height of eye.

Abdomen. Tergite 5 very short and triangular.

Distribution. Palaearctic - Sicily [Italy].

Biology. Unknown.

\section{Stevenia etrusca sp. nov.}

Type material. Holotype $0^{x}$ : ITALY - Toscana (Grosseto prov.) / Scarlino, Cala di Terra Rossa [4252'25.13"N 1046'28.42"E] / 02.VI.2004 (hand net) / P. Cerretti, D. Birtele, M. Tisato, D. Whitmore leg. [MZUR]. Paratypes: 3 우, same data as holotype [CNBF, CPC].

Etymology. From the Latin "Etruscus, Etrusca, Etruscum" meaning Etruscan, the ancient people of Etruria (= Tyrrhēnia) an area that covered part of what now are Emilia-Romagna, Tuscany, Umbria and Latium, and containing the type locality. The name should be treated as a Latin adjective.

Diagnosis. Male frons relatively broad and with proclinate orbital setae (Fig. 11); three katepisternal setae; abdomen black with a very narrow brownish rim on posterior margin of tergites $1+2$ and 3 in males (Figs. 12, 13); syntergite 1+2 with a pair of median marginal and median discal setae (Fig. 13). Abdominal tergites $1+2-4$ with transverse bands of microtrichosity on anterior $1 / 2-5 / 6$, interrupted medio-dorsally by a broad longitudinal black stripe; tergite 5 microtrichose on anterior 1/3-1/2 (Fig. 12).

Description [character states shared by S. etrusca and S. palermitana are omitted in the following description]

Male:

Length: $10.4 \mathrm{~mm}$.

Colour. Head black with grey microtrichosity; area between gena and parafacial reddish-yellow; scape and pedicel black or dark brown, postpedicel black; palpus yellowish to dark-brown. Thorax and legs black; scutum with three broad longitudinal dark vittae. Upper and lower calypters whitish. Wing hyaline or slightly infuscate; tegula black, basicosta yellow, veins light brown to dark brown. Abdomen (Figs. 12, 13) black, brownish at most on posterior rim of tergites 2 and 3; tergites 2-4 with transverse bands of white microtrichosity on anterior $1 / 2-5 / 6$, interrupted medio-dorsally by a broad longitudinal black stripe; tergite 5 microtrichose on anterior 1/3-1/2. Epandrium black. Sternite 5 black.

Head (Figs. 10, 11). Postpedicel about 1.3 times as long as pedicel. Frons at its narrowest point 0.77 times as wide as an eye in dorsal view. Ocellar setae short and weak (much shorter than the posterior frontal setae). Lateral vertical setae not differentiated from the postocular setae. One reclinate and 1 lateroclinate upper orbital setae (Figs. 10, 11); 1 proclinate orbital seta (Figs. 10, 11). Frontal setae descending to the level of proximal third of pedicel or slightly lower. Fronto-orbital plate with a row of short and stout proclinate setu- 
lae. Lower half of parafacial with a row of 5-7 long and stout medioclinate setae and several short proclinate setulae (Fig. 10). Parafacial at its narrowest point about as wide as the postpedicel. Lower facial margin slightly visible in lateral view. Vibrissa well developed and differentiated from sub-vibrissal setae. Gena in profile 0.47 times the vertical height of eye (height measured in the same vertical plane as height of head). Prementum about 3.5 times as long as wide.

Thorax. Three to 4 katepisternal setae. Scutellum with 3 pairs (basal, lateral and apical) of marginal setae; basal setae very short and weak, less than $1 / 2$ as long as laterals; lateral setae longer than the crossed apicals.

Legs. Fore leg: tibia with 3 anterodorsal setae. - Mid leg: tibia with 3-4 anterodorsal setae, 3-4 posterodorsal setae, usually 1 posterior seta; 1 ventral seta. - Hind leg: tibia with 3-4 long, robust anterodorsal and posterodorsal setae; with 3 dorsal preapical setae.

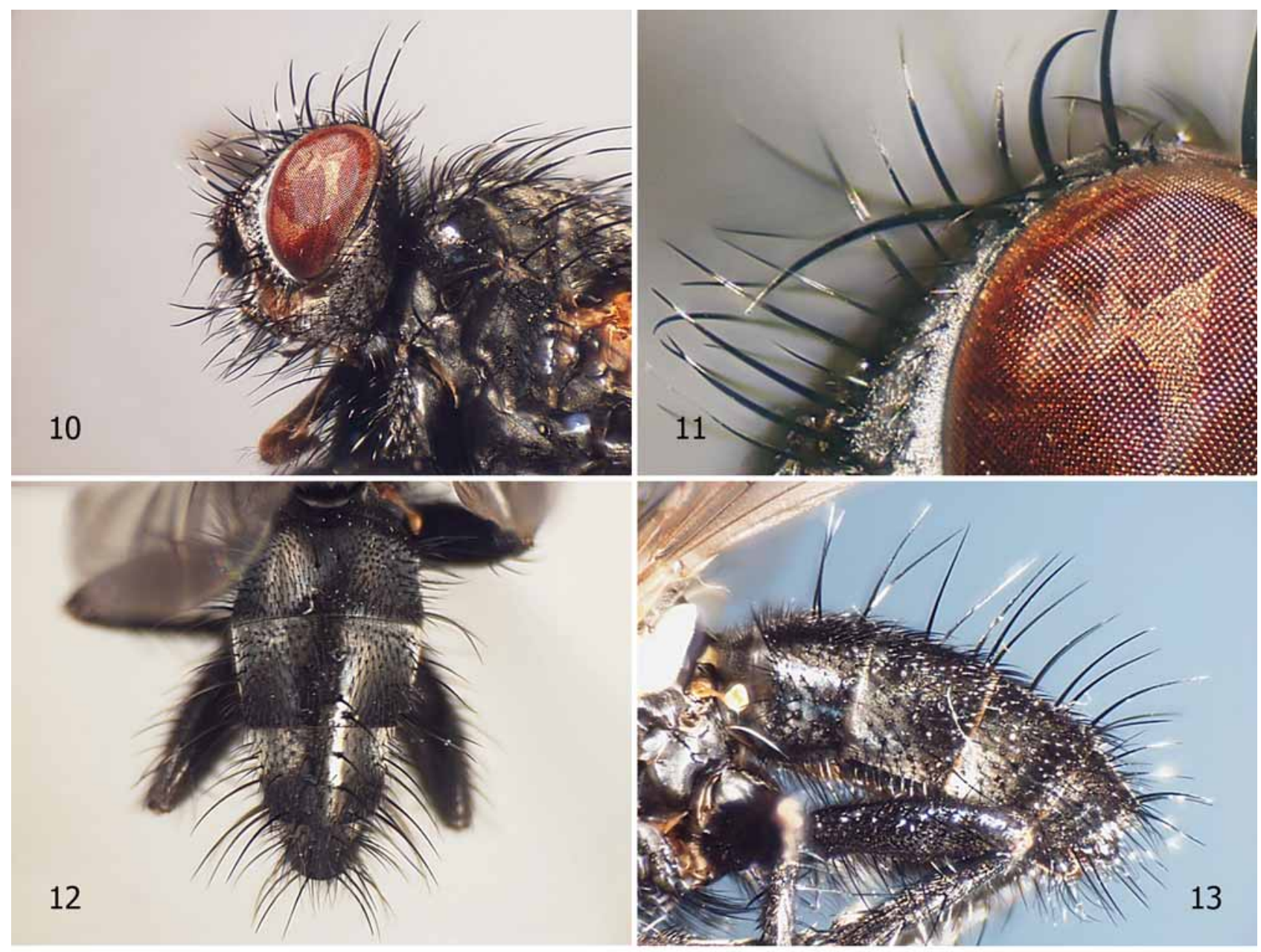

FIGURES 10-13. Stevenia etrusca sp. nov. (holotype). 10. Head and anterior half of thorax in lateral view. 11. Detail of fronto-orbital plate, with proclinate orbital seta. 12. Abdomen in dorsal view. 13. Abdomen in lateral view.

Abdomen (Figs 12,13). Syntergite 1+2 with 1 pair of median marginal and median discal setae and one or more lateral marginals. Tergite 3 with 1-2 pairs of median marginal and 1 pair of median discal setae. Tergite 4 with a row of marginal setae, 1-5 medio-discal setae. Tergite 5 with rows of marginal and discal setae.

Terminalia. Epandrial complex, sternite 5 and aedeagus very similar to those of S. palermitana, the only remarkable difference being the more strongly sclerotized dorsal sclerite of distiphallus.

Female, differs from male as follows:

Length: 8.7-9.7 mm.

Colour. Abdomen darker and with basal band of microtrichosity much weaker and sometimes indistinct and without a posterior rim. 

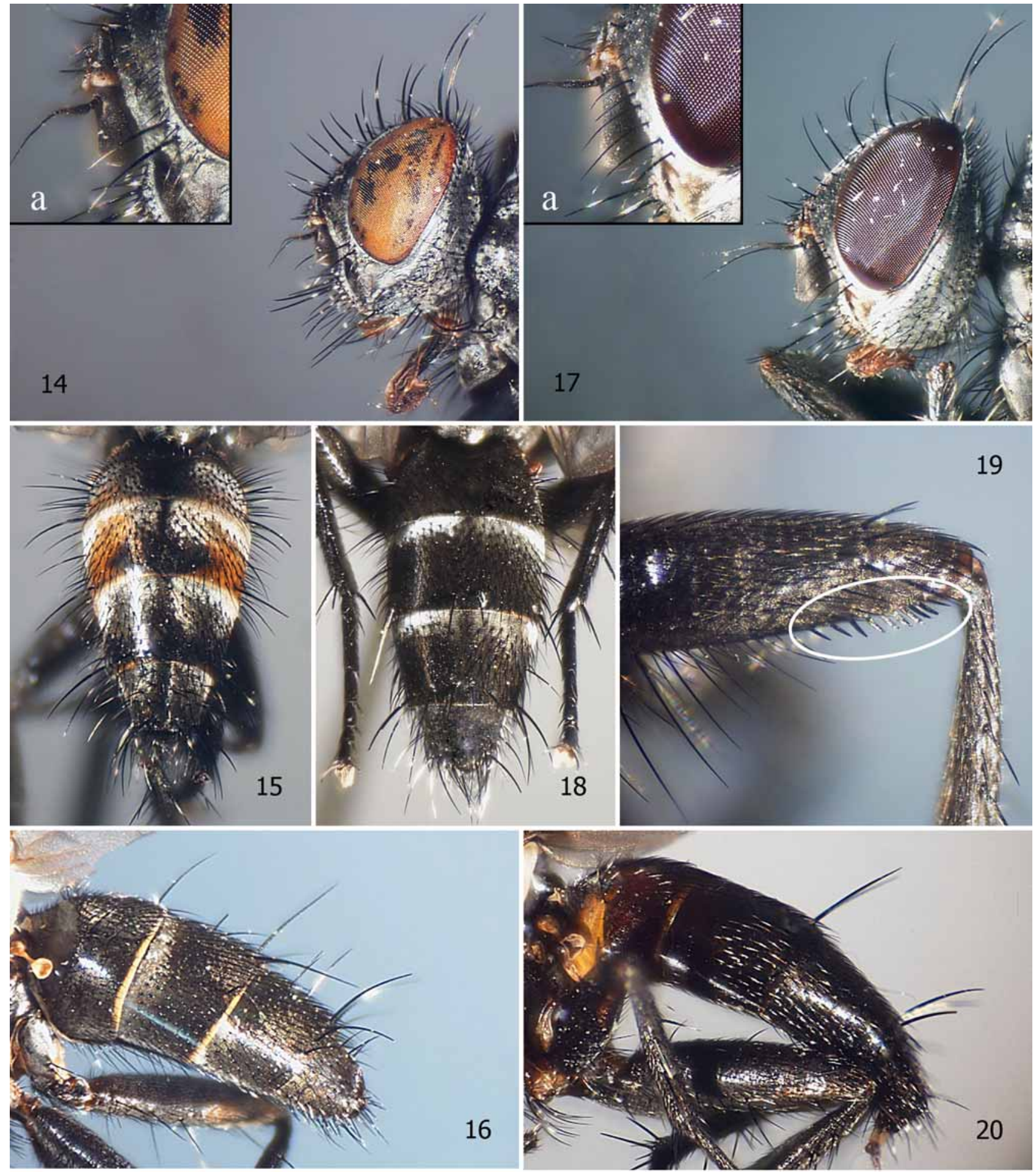

FIGURES 14-20. Stevenia spp. 14-16. S. deceptoria (Italy: Sicily). 14. Male head in lateral view, a) detail of antenna and parafacial. 15. Male abdomen in dorsal view. 16. Female abdomen in lateral view. 17. Male of S. fernandezi (Spain: Tenerife), head in lateral view, a) detail of antenna and parafacial. 18-19. Male of S. signata (Greece: Attika). 18. Abdomen in dorsal view. 19. Mid femur in posterior view, with ctenidium white circled. 20. Female of S. obscuripennis (Italy: Calabria), abdomen in lateral view.

Head. Frons wider, at its narrowest point $0.86-0.92$ times as wide as an eye in dorsal view. Fronto-orbital plate with 1-2 proclinate orbital setae (the posterior one usually lateroclinate). Parafacial (in lateral view) at its narrowest point $1.26-1.50$ times as wide as the postpedicel. Gena in profile $0.41-0.51$ times the vertical height of eye. 
Abdomen. Tergite 5 very short and triangular.

Distribution. Palaearctic - mainland Italy.

Biology. Unknown.

\section{Key to Palaearctic species of Stevenia}

Herting's (1961) key to Palaearctic species of the genus Stevenia is here expanded to include all species described subsequently. We have not been able to study material of S. maeotica Belanovsky and $S$. nudiseta Belanovsky (which incidentally were not included by Herting [1961]), and these species have been incorporated based on information in Stackelberg (1988).

1. Wing cell $r_{4+5}$ with a short petiole, about as long as crossvein $r-m$. acutangula Villeneuve

-- Petiole of $\mathrm{r}_{4+5}$ clearly longer than $\mathrm{r}-\mathrm{m}$ (as in Fig. 4) 2

2. Parafacial narrow, about 0.6-0.7 times as wide as postpedicel [measured at mid length], with setae arranged in a row along anterior margin and parafacial otherwise bare (Figs. 17, 17a). Postpedicel 1.7-2.0 times as long as pedicel (Fig. 17). [Endemic to Canary Islands] fernandezi Báez

-- Parafacial at least 0.9 times as wide as postpedicel, with setae usually arranged in an irregular patch between anterior margin of parafacial and eye (Figs 10,14), and if in a row-like arrangement then parafacial with scattered setulae (Fig. 2) and abdomen mainly black except for posterior 1/2-1/4 of tergite 5 which is red (Fig. 3). Postpedicel usually shorter (Figs. 1, 10, 14). [Species unknown from the Canary Islands].

3. Two katepisternal setae and abdominal syntergite $1+2$ with a pair of median marginal setae................... 4

-- Either three katepisternal setae, or two katepisternal setae and abdominal syntergite $1+2$ without median marginal setae.

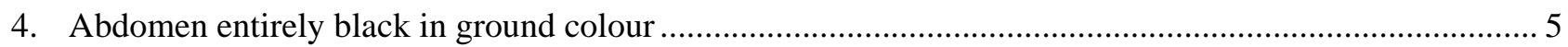

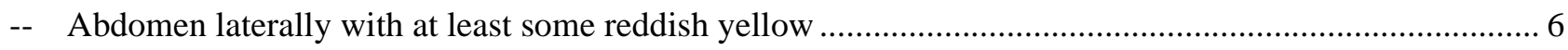

5. Presutural and prescutellar acrostichal setae present..................................................nudiseta Belanovsky

-- Presutural and prescutellar acrostichal setae absent (or very weak). hertingi Kugler

6. Frontal stripe just narrower than the fronto-orbital plate. Male mid- and hind tibiae ventrally with normal setae. Male mid femur with posteroventral ctenidium (as in Fig. 19). fausti (Portschinsky)

-- Frontal stripe broader than the fronto-orbital plate. Male mid- and hind tibiae ventrally with long and dense setae. Male mid femur without posteroventral ctenidium. lateralis (Macquart)

7. Abdominal syntergite $1+2$ without median marginal setae (Fig. 20) 8

-- Abdominal syntergite 1+2 with median marginal setae (Figs. 13, 16) 10

8. Arista bare. Scutellum with lateral seta closer to suture than to apical seta...... hirtigena Herting

-- Arista pubescent. Scutellum with lateral seta closer to apical seta than to suture... 9

9. Basicosta and proximal part of costa yellow. Male without proclinate orbital setae, female usually with two proclinate orbital setae. angustifrons (Villeneuve)

-- Basicosta yellow, contrasting to dark brown proximal part of costa. Male and female with one proclinate orbital seta. obscuripennis (Loew)

10. Only abdominal tergites 3 and 4 with a narrow basal band of microtrichosity, interrupted medio-dorsally (basal band sometimes indistinct or absent in female) (Fig. 18). Fore tibia with 0-3 posterodorsal setae. Arista with hairs at most as long as its maximum diameter. Abdomen without discal setae......

-- Abdominal microtrichosity also present on tergites 1+2 and 5 (Figs. 3, 12, 15), usually indistinct on syntergite $1+2$ in female. Fore tibia without posterodorsal setae. Length of hairs of the arista variable (longer or shorter than its maximum diameter). Median discal setae on abdominal tergites present or absent. ... 17 
11. Abdominal tergites 2-4 mainly reddish except for a median black-brown band, tergite 5 black-brown. Male: frons at its narrowest point about 1.3 times as wide as an eye in dorsal view; fronto-orbital plate with 2 proclinate orbital setae...... flaviventris Kugler

-- Abdomen mainly black but with or without lateral reddish markings. Male: frons at its narrowest point about $0.7-1.1$ times as wide as an eye in dorsal view; fronto-orbital plate with $0-1$ proclinate orbital setae

12. Vein $\mathrm{R}_{4+5}$ setose about half way to crossvein $\mathrm{r}-\mathrm{m}$. Both sexes with a proclinate orbital seta

umbratica (Fallén)

-- Vein $\mathrm{R}_{4+5}$ with setae only at base. Proclinate orbital seta may or may not be present in male [The females of S. eggeri, S. kugleri, S. maeotica, S. pannonica, S. signata, and S. triangulata cannot be distinguished at present]

13. Male with a proclinate orbital seta (as in Fig. 10) ...

-- Male without a proclinate orbital seta (as in Figs. 1, 14, 17)...

14. Male: mid femur without posteroventral ctenidium; frons at least as wide as an eye in dorsal view .triangulata (Loew)

-- Male: mid femur with posteroventral ctenidium (Fig. 19); frons at its narrowest point $0.7-1.1$ times as wide as an eye in dorsal view

15. Male: frons at its narrowest point about $0.7-0.8$ times as wide as an eye in dorsal view; abdomen from partly reddish laterally to entirely black [specimens from Greece (CPC)] signata (Mik)

-- Male: frons at its narrowest point about 1.0-1.1 times as wide as an eye in dorsal view; abdomen entirely black kugleri Herting

16. Abdomen with broad red markings laterally pannonica Villeneuve

-- Abdomen entirely black or with at most an indication of reddish colour laterally eggeri (Strobl) and maeotica Belanovsky

17. Lateral vertical seta well developed, clearly longer than the postocular setae. Arista with hairs longer than its maximum basal diameter. Fronto-orbital plate almost bare, with only a few hair-like setulae. Both sexes with a ventral seta on mid-tibia. Body entirely black, very sparsely microtrichose

atramentaria (Meigen)

-- Lateral vertical seta not differentiated from the postocular setae. Hairs of the arista at most as long as the maximum basal diameter of the arista. Male: fronto-orbital plate with at least a row of short proclinate setulae lateral to frontal setae; mid-tibia with or without ventral seta. Body colour variable. Microtrichosity more marked at least in males ....

18. Male: fronto-orbital plate with a pair of proclinate and a pair of lateroclinate orbital setae (Figs. 10, 11); mid tibia with a ventral seta; abdomen entirely black, with a very narrow brownish rim on posterior margin of tergites $1+2$ and 3, indistinct medially (Fig. 12); tergites $1+2$ to 4 with a pair of median discal setae (Fig 13). Female: abdominal tergites entirely black, without posterior brownish rim; posterior orbital seta lateroclinate. Body length: 8.7-10.4 mm... etrusca sp. nov

-- Male fronto-orbital plate without proclinate orbital setae (Figs 1, 14); mid tibia usually without ventral seta (sometimes present in $S$. palermitana); abdominal tergites $1+2$ and 3 with at least a clear posterior yellowish margin, often reddish laterally (S. deceptoria) (Fig. 15) or with a red tip of tergite 5 (S. palermitana) (Fig. 3); median discal setae may or may not be present. Female: abdominal tergites black with a clear posterior yellowish margin; fronto-orbital plate usually without lateroclinate orbital setae. Body length: $5.0-9.0 \mathrm{~mm}$.

19. Abdomen mainly black except for posterior $1 / 2-1 / 4$ of tergite 5 which is red (Fig. 3). Parafacial with a row of 5-7 long and stout medioclinate setae and several short proclinate setulae (Figs 1,2). Male: distiphallus in ventral view as in Fig. 6 ......

palermitana sp. nov.

-- Abdomen not as above; tergites $1+2$ to 4 usually with a clear yellow posterior margin, and more or less 
red laterally, tergite 5 entirely black (Fig. 15). Parafacial with 2-3 (rarely 4) strong setae on lower 1/3-1/2 (Figs. 14, 14a). Male distiphallus in ventral view as in Fig. 9. deceptoria (Loew)

\section{Acknowledgements}

We are grateful to Mr Daniele Avesani, Centro Nazionale Biodiversità Forestale, Verona, for helping us compose the plates. Dr. Hans-Peter Tschorsnig, Staatliches Museum für Naturkunde, Stuttgart, kindly assisted with a photocopy of the relevant part of Belanovsky's (1951) monograph and critically revised the manuscript.

\section{References}

Báez, M. (1979a) Stevenia fernandezi n.sp. (Dipt. Rhinophoridae) de las Islas Canarias. Vieraea, 8, 23-26.

Báez, M. (1979b) The genus Phyto in the Canary Islands. Nouvelle Revue d'Entomologie, 9, 161-164.

Báez, M. (1988) Una nueva especie de Phyto (Robineau-Desvoidy, 1830) en las Islas Canarias (Diptera, Rhinophoridae). Boletin de la Asociación española de Entomología, 12, 99-103.

Belanovsky, J.D. (1951) Takhiny Ukrainskoi SSR, Vol. 1. Kiev, 191 pp.

Bürgis, H. (1991) Die unendliche Geschichte: Parasitische Hautflügler aus Puparien der in Asseln schmarotzenden Asselfliegen. Teil 1: Eine neue Wespe. Mikrokosmos, 80, 295-299.

Bürgis, H. (1992) Die unendliche Geschichte Parasitische Hautflügler aus Puparien der in Asseln schmarotzenden Asselfliegen Teil 4: Die Asselfliege, Schlußbemerkungen. Mikrokosmos, 81, 100-104.

Colless, D.H. (1994) A new family of muscoid Diptera from Australasia, with sixteen new species in four new genera (Diptera: Axiniidae). Invertebrate Taxonomy, 8, 471-534. [Pp. 528-534, appendix authored by J.W.O. Ballard.]

Crosskey, R.W. (1977) A review of the Rhinophoridae (Diptera) and a revision of the Afrotropical species. Bulletin of the British Museum (Natural History), Entomology series, 36 (1), 1-66.

Evenhuis, N.L. \& Thompson, F.C. (1990) Type designations of genus-group names of Diptera given in d'Orbigny's Dictionnaire Universel d'Histoire Naturelle. Bishop Museum Occasional Papers, 30, 226-258.

Herting, B. (1961) 64e. Rhinophorinae. In: Lindner, E. (Ed.), Die Fliegen der palaearktischen Region, 216. E. Schweizerbart'sche Verlagsbuchhandlung, Stuttgart, pp 1-36.

Herting, B. (1966) Diptera from Nepal: a new species of Rhinophoridae. Bulletin of the British Museum (Natural History), Entomology series, 17, 10.

Herting, B. (1993) Family Rhinophoridae. In: Soós, Á. \& Papp, L. (Eds.), Catalogue of Palaearctic Diptera, Vol. 13, Anthomyiidae - Tachinidae. Hungarian Natural History Museum, Budapest, pp. 102-117.

Kugler, J. (1978) The Rhinophoridae (Diptera) of Israel. Israel Journal of Entomology, 12, 65-106.

Meigen, J.W. (1824) Systematische Beschreibung der bekannten europäischen zweiflügeligen Insekten 4, Hamm, xii + $428 \mathrm{pp}$.

Merz, B. \& Haenni, J.-P. (2000) 1.1. Morphology and terminology of adult Diptera (other than terminalia). In: Papp, L. \& Darvas, B. (Eds.), Contribution to a Manual of Palaearctic Diptera (with special reference to flies of economic importance). Vol. 1. General and Applied Dipterology. Science Herald, Budapest, pp. 21-51.

O'Hara, J.E. (2002) Revision of the Polideini (Tachinidae) of America north of Mexico. Studia dipterologica, Supplement, 10, 1-170.

D’Orbigny, C.V.D., ed. 1848. Dictionnaire universel d'histoire naturelle résumant et complétant tous les faits présentés par les encyclopédies les anciens dictionnaires scientifiques les oeuvres complètes de Buffon, et les traités spéciaux sur les diverses branches des sciences naturelles donnant la description des êtres et des divers phénomènes de la nature l'étymologie et la définition des noms scientifiques, les principales applications des corps organiques et inorganiques à l'agriculture, à la médecine, aux arts industriels, etc.; dirigé par M. Charles d'Orbigny, et enrichi d'un magnifique atlas de 288 planches gravées sur acier. Tome onzième. C. Renard, Paris, 816 pp.

Pape, T. (1985) A new species of Baniassa Kugler from Iraq (Diptera: Rhinophoridae). Entomologica scandinavica, 16, $209-211$.

Pape, T. (1986) A phylogenetic analysis of the woodlouse-flies (Diptera, Rhinophoridae). Tijdschrift voor Entomologie, $129,15-34$.

Pape, T. (1987a) A new Afrotropical species of Phyto Robineau-Desvoidy (Diptera: Rhinophoridae). Journal of the Entomological Society of Southern Africa, 50, 375-381.

Pape, T. (1987b) Species of the Afrotropical genus Ventrops Crosskey (Diptera: Rhinophoridae). Annals of the Natal Museum, 28, 543-550. 
Pape, T. (1989) A revision of the Rhinophoridae (Diptera) described by C. Rondani. Entomologica scandinavica, 19, $355-358$.

Pape, T. (1997) Two new species of the Phyto carinata species-group (Diptera: Rhinophoridae). Annals of the Natal Museum, 38, 159-168.

Pape, T. (1998) 3.53. Family Rhinophoridae. In: Papp, L. \& Darvas, B. (Eds.), Contribution to a Manual of Palaearctic Diptera (with special reference to flies of economic importance). Vol. 3. Higher Brachycera. Science Herald, Budapest, pp. 679-689.

Pape, T. \& Arnaud, P.H., Jr. (2001) Bezzimyia - a genus of New World Rhinophoridae (Insecta, Diptera). Zoologica Scripta, 30, 257-297.

Pape, T. \& Kurahashi, H. (1994) First records of Rhinophoridae (Insecta: Diptera) from Japan. Japanese Journal of Entomology, 62, 475-481.

Peris, S.V. (1963) Sobre los Rhinophorinae españoles con descripción de una nueva especie de Chaetostavenia [sic] de Marruecos (Dipt., Calliphoridae). Eos - Revista española de Entomología, 38, 601-609.

Robineau-Desvoidy, J.B. (1830) Essai sur les Myodaires. Mémoires présentés par divers Savants à l'Académie Royale des Sciences de l'Institut de France, 2, Paris, 1-813.

Stackelberg, A.A. (1988) Family Rhinophoridae. In: Bei-Bienko, G.Ya. (Ed.), Keys to the Insects of the European part of the USSR, Vol. 5(2), 1097-1102. Smithsonian Institution Libraries, Washington, D.C. [English translation of original Russian version from 1970.]

Stuckenberg, B.R. (1999) Antennal evolution in the Brachycera (Diptera) with a reassessment of terminology relating to the flagellum. Studia dipterologica, 6, 33-48.

Thompson, F. C. (Ed.) (2006) Biosystematic Database of World Diptera, Version 8.5. Online at http://www.diptera.org/ biosys.htm, accessed on 2 April 2007.

Tschorsnig, H.-P. (1985) Die Struktur des männlichen Postabdomens der Rhinophoridae (Diptera). Stuttgarter Beiträge zur Naturkunde (A), 375, 1-18.

Tschorsnig, H.-P. \& Richter, V.A. (1998) 3.54. Family Tachinidae. In: Papp, L. \& Darvas, B. (Eds.), Contribution to a Manual of Palaearctic Diptera (with special reference to flies of economic importance). Vol. 3. Higher Brachycera. Science Herald, Budapest, pp. 691-827.

Verves, Yu.G. 2005. A checklist of the Ukrainian Rhinophoridae (Diptera). Studia dipterologica, 11, 609-613. 
